\title{
Editorial JeDEM 7(2) 2015: CeDEM 15
}

\section{Noella Edelmann, Peter Parycek, Judith Schossböck}

\author{
Centre for E-Governance, Danube University Krems, Dr. Karl Dorrek-Straße 30, A-3500 Krems. \\ \{noella.edelmann, peter.parycek, judith.schossboeck\}donau-uni.ac.at
}

In this issue of JeDEM, we are pleased to include the keynotes by Shauneen Furlong and Alon Peled held at the CeDEM15 Conference at Danube University Krems, research papers from CeDEM and a paper submitted to the JeDEM open submission system. Whilst the keynotes' articles describe the challenges to transformational government and the linking (or "wazing") of the world's government data resources, the authors investigate transparency in open governments, the critical factors in the use and publication of open data, the motivation to share knowledge in public administrations using new media technologies, as well as cities' commitment to open data. The selection of research papers show that whilst "openness" and "transparency" are key issues in e-democracy and open government, they clearly contain a variety of dimensions that need to be analysed in different contexts, using diverse examples and perspectives.

Shauneen Furlong, based in Canada, but with her eyes on developments all over the world, addresses the hope and promise of e-government to revitalise and modernise public services. Unfortunately, she claims, e-government has not achieved this and is instead characterised by high rates of failure. What is supposed to be "transformational e-government", Shauneen describes as slow, halting and based on managing assets rather than changing and creating new management capacities. Governments rely heavily on project management, and so, for e-government to be successful, needs to be effective, less process bound, more results-driven and change-oriented.

Another issue that governments are confronted with are the massive amounts of data they deal with. So Alon Peled assumes that, surely, this must mean that governments are experts in data integration and sharing? The reality is that poor information sharing lead to the $9 / 11$ attacks, but also prevented successful relief efforts following Hurricane Katrina and the 2011 Tohoku tsunami. In addition, governments have no incentive to share. So Alon, together with Steven Karas, used select incentives to encourage government officials to exchange data in an automated Public Sector Information Exchange (PSIE). With PSIE they created the world's first, fully-automated, and biggest OGD metadata. "Biggest" means: 400,000 OGD information assets from 24 countries in 14 different languages, translated as $4.75 \mathrm{~GB}$ of metadata of government data available on the web. And what can you do with this? Read Alon's suggestions, we don't want to ruin the surprise for you, just note that "PSIE data empowers you to do all that and more!"

Different groups of users are central to any discussion about open government and open data. In the paper Motivational Aspects of Knowledge Sharing through Web 2.0 Technologies in Public 
Administration, Markus Wojtczak and Michèle Morner look beyond public administrations' use of social media technologies to see how administrations engage and collaborate with citizens to generate new knowledge. They apply the Theory of Planned Behaviour (Ajzen, 2012) to understand users' motivation to share their knowledge, a factor critical for the success of collaborative websites and often linked to a problem sometimes known as "if you build, will they come?". Beyond reviewing the literature on voluntary knowledge sharing in organizations, they look at how results gathered from research so far can be applied to citizen-administration online collaboration, suggest how to foster citizens' motivation and present ideas for further research in this area.

The paper titled Refereeing eParticipation in the Newsroom: The Work Routines and Competences of a News Portal's Discussion Administrators, also focuses on the users and their use of technology and media. Based on a case-study of a Slovak newspaper, Simon Smith investigates the technological change associated with participatory tools in journalism. Drawing on interviews and ethnographic observation in the newsroom, Smith puts some myths about journalism and e-participation into perspective, and offers important insights about how newspapers cope with additional tasks resulting from the need to integrate and negotiate user-generated content. He points out how the administrative work needed for these tasks requires a set of competences different from the editorial skills normally prioritised in journalism. Nevertheless and probably surprising, this has little to do with community building. What does it then mean to be a competent referee of internet discussion? Find out yourself.

In Transparency and Open Government: Reporting on the Disclosure of Information, Victoria L. Lemieux, Stephanie E. Trapnell, Jessie Worker and Carole Excell examine trends in Right To Information (RTI) and the respective laws, i.e. how countries are collecting and publishing data - a process new information technologies have contributed to together with a growing demand for participatory governance and global developments. By assessing statistics from Brazil, India, Jordan, Mexico, South Africa, Thailand, the United Kingdom and the United States, and by analysing the data about requests, complaints and appeals on responsive disclosure, they find that these practices are far from standardized and data often unavailable and incomplete. The results presented are part of a larger study for the World Bank on the effective implementation of RTI laws.

Anneke Zuiderwijk, Iryna Susha, Yannis Charalabidis, Peter Parycek and Marijn Janssen's paper on open data publication focuses on the actual use of open data, but also consider the factors necessary for evaluating it (and its success). With Critical Factors for Open Data Publication and Use: A Comparison of City-level, Regional, and Transnational Cases, they react to the lack of research on the factors that determine the success or failure of open data initiatives and provide a categorisation of possible success factors. While the critical success factors seem to derive from many of those categories, it can be said that some appear to be more universally applicable than others. By examining a number of case studies in different project contexts, namely the initiatives ENGAGE, Open New York and Open Vienna, the researchers derived twelve success factors that were deemed critical to all three cases. 
But can we monitor the evolution of open government data (OGD) behavior and commitment over time? Can we compare the OGD behavior and commitment of different governmental entities? On the municipal level, yes. Karine Nahon, Alon Peled, Jennifer Shkabatur analysed the OGD behavior of 16 US cities over a period of four years, based on both quantitative and qualitative data. Their framework won the best paper award of this year's CEDEM15 with their paper OGD Heartbeat: Cities' Commitment to Open Data. They examined cities' commitment to the concept of Open Government Data and classified it by different levels. While level "Way of Life" indicates a high commitment, "Lip Service" refers to scarce or no commitment. Curious about the heartbeat of a specific city? Have a look.

An example of government openness at municipal level and citizen use is provided by Derek Lackaff, who in his paper Escaping the Middleman Paradox: Better Reykjavik and Open Policy Innovation uses the 2008 kreppa (crisis) in Iceland that kick-started the global financial crisis. His case study focuses on "Better Reykjavik", a municipal e-petition website. The study, embedded within Coleman's framework, describes and analyses the development of a consultation website, used at first by the angry Icelandic citizens to protest against a corrupt government, to become the Better Reykjavik platform, now a central part of Icelandic government. Derek shows how the online consultation website moved from the outside ("the fringes of the grassroots") to the inside ("the center of public and governmental awareness"), that is, became the normal channel used for citizen-government interaction. In describing the particularities of the website, its development and use, Derek not only describes a particular episode of citizen-government interaction, but extrapolates both the meaning and impact a bottom-up, fast-moving technical initiative can have on the slower-moving processes of democratic governance.

Another example is provided by Nicolás Mendoza in his contribution Liquid Separation: Three Fundamental Dimensions within LiquidFeedback and other Voting Technologies. Nicolás looks at LiquidFeedback as a digital platform beyond the hype of voting technologies and liquid democracy tools, and asks whether such a platform can accurately perceive the political will of participants, and if it can meaningfully, fairly and safely change the state of affairs of society. As a result of interviews and critical analysis, three dimensions relevant for all voting technologies are proposed: Expressivity, influence and integrity. Integrity in this case means that the individual should expect no personal negative consequences from using the technology, and that the community should benefit because the results reflect the views of its members or participants. Even if the implementation of the concept has had its flaws in the past and many liquid tools have been taken down recently, it is, Mendoza concludes, providing value in the search for better democratic arrangements.

We hope that you enjoy reading this issue as much as we do and and look forward to hearing from you as authors, reviewers or guest editors. JeDEM welcomes your articles throughout the year (open submission system) or in response to one of our calls (special issue). Or, if you would like to review papers submitted to the journal, please do not hesitate to get in touch or sign up at our website.

In the meantime, we wish you a Merry Christmas and a Happy New Year: $\underline{w w w . d o n a u-}$ uni.ac.at/xmas! 


\begin{abstract}
About the Editors
Noella Edelmann

Noella is a research fellow at the Center for E-Governance at the Danube University. Her main research interests are the psychological aspects of behaviour on the internet and Open Access. She is Co-chair of the Conference for E-Democracy and Open Government and managing editor of the international open access e-journal for E-Democracy and Open Government (JeDEM). Noella Edelmann completed her Psychology and English Degree at the University of Strathclyde, UK and Masters' Degrees at the University of London, UK and the Danube University Krems, Austria.
\end{abstract}

Peter Parycek

Peter Parycek is Professor for E-Governance and Head of the Department for E-Governance at the Danube University Krems. As a lawyer and graduate of the Master's program Telematics, his work is at the intersection of legal policy, social and technological developments. His research and project priorities include eGovernance, eDemocracy and eGovernment. He is responsible for the conference series CeDEM (International Conference for E-Democracy and Open Government) and the open access journal JeDEM (eJournal of eDemocracy and Open Government).

\title{
Judith Schossböck
}

Judith Schossböck is a research fellow at the Centre for E-Governance at Danube University Krems, Austria and managing editor of the open access e-journal JeDEM (jedem.org). Among her research interests are edemocracy, online activism and digital literacy. She was inter alia involved in a study on the internet skills of the 14 years old youth in Austria and the development of a youth participation platform on which four European countries cooperated. She currently works on a project researching online identification in e-participation. 